\title{
BMJ Open Association between refill adherence to lipid-lowering medications and the risk of cardiovascular disease and mortality in Swedish patients with type 2 diabetes mellitus: a nationwide cohort study
}

\author{
Sofia Axia Karlsson, ${ }^{1}$ Christel Hero, ${ }^{2}$ Ann-Marie Svensson, ${ }^{3}$ Stefan Franzén, ${ }^{3}$ \\ Mervete Miftaraj, ${ }^{3}$ Soffia Gudbjörnsdottir, ${ }^{2,3}$ Katarina Eeg-Olofsson, ${ }^{2}$ \\ Björn Eliasson, ${ }^{2}$ Karolina Andersson Sundell ${ }^{1,4}$
}

To cite: Karlsson SA, Hero C, Svensson A-M, et al. Association between refill adherence to lipid-lowering medications and the risk of cardiovascular disease and mortality in Swedish patients with type 2 diabetes mellitus: a nationwide cohort study. BMJ Open 2018;8:e020309. doi:10.1136/ bmjopen-2017-020309

- Prepublication history and additional material for this paper are available online. To view these files, please visit the journal online (http://dx.doi. org/10.1136/bmjopen-2017020309).

Received 27 October 2017 Revised 5 February 2018 Accepted 28 February 2018

Check for updates

${ }^{1}$ Department of Public Health and Community Medicine, Sahlgrenska Academy, University of Gothenburg, Gothenburg, Sweden ${ }^{2}$ Department of Molecular and Clinical Medicine, Sahlgrenska Academy, University of Gothenburg, Gothenburg, Sweden

${ }^{3}$ National Diabetes Register, Centre of Registers, Gothenburg, Sweden

${ }^{4}$ AstraZeneca, Medical Evidence and Observational Research, Gothenburg, Sweden

Correspondence to Sofia Axia Karlsson; sofia.karlsson@gu.se

\section{ABSTRACT}

Objectives To analyse the association between refill adherence to lipid-lowering medications, and the risk of cardiovascular disease (CVD) and mortality in patients with type 2 diabetes mellitus.

Design Cohort study.

Setting National population-based cohort of Swedish patients with type 2 diabetes mellitus.

Participants 86568 patients aged $\geq 18$ years, registered with type 2 diabetes mellitus in the Swedish National Diabetes Register, who filled at least one prescription for lipid-lowering medication use during 2007-2010, 87\% for primary prevention.

Exposure and outcome measures Refill adherence of implementation was assessed using the medication possession ratio (MPR), representing the proportion of days with medications on hand during an 18-month exposure period. MPR was categorised by five levels $(\leq 20 \%$, $21 \%-40 \%, 41 \%-60 \%, 61 \%-80 \%$ and $>80 \%$ ). Patients without medications on hand for $\geq 180$ days were defined as non-persistent. Risk of CVD (myocardial infarction, ischaemic heart disease, stroke and unstable angina) and mortality by level of MPR and persistence was analysed after the exposure period using Cox proportional hazards regression and Kaplan-Meier, adjusted for demographics, socioeconomic status, concurrent medications and clinical characteristics.

Results The hazard ratios for CVD ranged 1.33-2.36 in primary prevention patients and 1.19-1.58 in secondary prevention patients, for those with MPR $\leq 80 \%(p<0.0001)$. The mortality risk was similar regardless of MPR level. The CVD risk was $74 \%$ higher in primary prevention patients and $33 \%$ higher in secondary prevention patients, for those who were non-persistent $(p<0.0001)$. The mortality risk was $6 \%$ higher in primary prevention patients and $18 \%$ higher in secondary prevention patients, for nonpersistent patients $(p<0.0001)$.

Conclusions Higher refill adherence to lipid-lowering medications was associated with lower risk of CVD in primary and secondary prevention patients with type 2 diabetes mellitus.

\section{Strengths and limitations of this study}

- The association between refill adherence to lipid-lowering medications, and the risk of cardiovascular disease (CVD) and mortality was assessed for 86568 Swedish patients with type 2 diabetes mellitus.

- We assessed the risk of CVD and mortality by five different levels of implementation to lipid-lowering medications.

- Only patients who survived the exposure period of 18 months were eligible for inclusion in the analysis, meaning we might have excluded the most fragile patients.

\section{INTRODUCTION}

Cardiovascular disease (CVD) is the major cause of death in patients with type 2 diabetes mellitus. ${ }^{12}$ A recent Swedish study showed that the mortality rate from CVD decreased among patients with type 2 diabetes mellitus in 1998-2014; however, the reduction was not as great as among patients without type 2 diabetes mellitus. The risk of CVD for people with diabetes mellitus is multifactorial and related to hyperglycaemia, comorbidities (hypertension, dyslipidaemia, obesity, and so on) and lifestyle factors (eg, physical inactivity, diet, smoking, and so on). For these reasons, the recommended diabetes treatment includes glucose-lowering medications combined with antihypertensive and lipid-lowering medications, as well as lifestyle changes. ${ }^{3} 4$ Treatment with lipid-lowering medications has been shown to reduce the risk of CVD in patients with type 2 diabetes mellitus. ${ }^{5-7}$

Adherence is crucial to establishing the long-term effects of medications. ${ }^{5-7}$ 
Adherence, that is, the extent to which patients take medications as prescribed, includes initiation, implementation and discontinuation of medication use. ${ }^{8}$ Initiation indicates when the first dose is taken and discontinuation defines the last dose. Implementation is often measured as a percentage and represents the extent to which patients' actual dosing corresponds to the recommended regimen. ${ }^{910}$ Persistence represents the length of time from initiation to discontinuation of treatment and reflects continuity. ${ }^{811}$ Using dispensing data for lipid-lowering medications, previous studies have reported implementation as varying between $66 \%$ and $87 \%^{11-14}$ in patients with diabetes mellitus and/or previous CVD; high implementation $(>80 \%)$ to statins was associated with lower risk of $\mathrm{CVD}^{56}$ and mortality. ${ }^{15}$

The studies dichotomously categorised implementation when analysing association with the risk of CVD and mortality. Thus, they do not provide any information about the risk of CVD and mortality by level of implementation. From a clinical perspective and to motivate patients, it is important to know whether there is any significant benefit of complete adherence and whether taking medications every other day offers any advantages. For that reason, this study analysed the association between different levels of implementation and persistence to monotherapy of lipid-lowering medications and the risk of CVD and mortality in Swedish patients with type 2 diabetes mellitus. Furthermore, we assessed the results for patients receiving lipid-lowering medications as primary and secondary prevention.

\section{METHODS}

\section{Data sources}

This is a nationwide study that linked individual data from five national registers using national personal identity numbers: (1) the Swedish Prescribed Drug Register (SPDR) contains information about all medications dispensed at pharmacies since 1 July $2005 .{ }^{16}$ The data include information about the patient and the prescriber as well as the dispensed medications (date, medication type, package size, dosage instructions, and so on); (2) patient data are continuously reported to the National Diabetes Register (NDR) by physicians and nurses at hospitals and primary care clinics by means of electronic charts or entered online in the NDR. All patients give their informed consent for inclusion in the register. The register provides information on risk factors and potential complications of diabetes mellitus ${ }^{17}$; (3) the National Patient Register contains information about admissions for inpatient and outpatient care $^{18}$; (4) the Cause of Death Register contains information about the cause of death since the 1960s; and (5) the Longitudinal Integration Database for Health Insurance and Labour Market Studies (LISA) provides individual information about socioeconomic characteristics on an annual basis. ${ }^{19}$ The SPDR, the NDR, the National Patient Register and the Cause of Death Register are all administered by the
Swedish National Board of Health and Welfare, and the LISA database is managed by Statistics Sweden. The national personal identity number is assigned at the time of birth or immigration, making data linkage virtually complete.

\section{Study population and period}

This study included new Swedish users of lipid-lowering medications (Anatomical Therapeutic Chemical (ATC): C10) with type 2 diabetes mellitus. Patients aged 18 years or older entered with type 2 diabetes mellitus in the NDR who filled at least one prescription for lipid-lowering medications between 1 January 2007 and 31 December 2010 (index period) were identified in the SPDR. Patients with type 2 diabetes mellitus were defined as those treated with diet only and/or glucose-lowering medications other than insulin, or onset of diabetes aged 40 years or older and treated with insulin and/or other glucose-lowering medications. ${ }^{20}{ }^{21}$ New users were defined as patients with no filled prescriptions for lipid-lowering medications for 1 year prior to the first one during the index period (index date). The study period was broken down into two intervals (exposure and outcome) to avoid confounding refill adherence with the outcomes (CV events and mortality).

During the exposure period, when refill adherence was assessed, all patients were followed for 18 months as of the index date. Patients who experienced a CV event, migrated or died during the period were excluded. Furthermore, patients were excluded if they filled prescriptions for: (1) multidose dispensed medications (ie, doses dispensed in series of single sachets) that were automatically dispensed without having been collected; (2) extemporaneous preparations that lacked information on package size; (3) bile acid sequestrants that are generally prescribed for indications other than hyperlipidaemia; or (4) combination therapy of multiple substances and/or strengths since they fall outside the scope of this study. Combination therapy was defined as having filled prescriptions for (1) multiple lipid-lowering substances or multiple strengths of the same substance on the same date, or (2) another substance/strength for 45 or fewer days between two fills of the same substance/ strength. Preparations containing a fixed dose combination of lipid-lowering medications in the same tablet were regarded as monotherapy.

During the outcome period, each patient was followed from the first day after the exposure period until migration, CV event, death or 31 December 2013, whichever occurred first.

\section{Exposure: refill adherence}

For each patient, refill adherence was estimated during an 18-month exposure period with data from the SPDR. The length of the exposure period was defined to ensure stable adherence estimates when under the Swedish Pharmaceutical Benefit Scheme. ${ }^{22}$ All patients were assumed to initiate lipid-lowering medications on the index date. Implementation was measured from initiation to the last 
day of the exposure period using the medication possession ratio (MPR), which represents the proportion of days with medications on hand during the exposure period. A detailed description of the assessment of MPR has been described elsewhere. ${ }^{23}$ The supply of each prescription was estimated by dividing the number of tablets filled by the daily dosage. Overlapping supplies of filled prescriptions for the same substance and strength were added to the duration of the subsequent prescription. If the overlapping supplies contained different substances or strengths, they were deleted. Supplies past the final observation date were deleted as well. MPR was broken down into five categories $(\leq 20 \%, 21 \%-40 \%, 41 \%-60 \%$, $61 \%-80 \%$ and $>80 \%$ ) and MPR $>80 \%$ was considered the reference for the statistical analyses. Patients were defined as non-persistent if they discontinued lipid-lowering treatment during the exposure period. Discontinuation was defined as a gap of at least 180 days between two filled prescriptions for lipid-lowering medications.

\section{Outcome: CVD and mortality}

The primary outcomes were risk of CVD and mortality identified from the National Patient Register and the Cause of Death Register using International Statistical Classification of Diseases and Related Health Problems (ICD) codes. CVD was defined as hospitalisation for unstable angina pectoris, myocardial infarction (including percutaneous coronary intervention and coronary artery bypass grafting), ischaemic heart disease or stroke (for

Table 1 Cardiovascular disease and mortality defined by ICD-10 and surgical procedure codes

\begin{tabular}{|c|c|c|}
\hline Complication & ICD-10 & $\begin{array}{l}\text { Surgical } \\
\text { procedure codes }\end{array}$ \\
\hline $\begin{array}{l}\text { Unstable angina } \\
\text { pectoris }\end{array}$ & 120 & \\
\hline $\begin{array}{l}\text { Myocardial } \\
\text { infarction (including } \\
\text { percutaneous } \\
\text { coronary } \\
\text { intervention and } \\
\text { coronary artery } \\
\text { bypass grafting) }\end{array}$ & 121 & $\begin{array}{l}\text { FNA00, FNA10, } \\
\text { FNA20, FNA96, } \\
\text { FNB00, FNB20, } \\
\text { FNB96, FNC10, } \\
\text { FNC20, FNC30, } \\
\text { FNC40, FNC50, } \\
\text { FNC60, FNC96, } \\
\text { FND10, FND20, } \\
\text { FND96, FNE00, } \\
\text { FNE10, FNE20, } \\
\text { FNE96, FNF00, } \\
\text { FNF10, FNF20, } \\
\text { FNF30, FNF96, } \\
\text { FNG00, FNG02, } \\
\text { FNG05, FNG06, } \\
\text { FNG10, FNG30, } \\
\text { FNG96 }\end{array}$ \\
\hline $\begin{array}{l}\text { Ischaemic heart } \\
\text { disease }\end{array}$ & $122,123,124,125$ & \\
\hline Stroke & $161,163,164,167.9$ & \\
\hline
\end{tabular}

ICD-10, International Statistical Classification of Diseases and Related Health Problems 10th Revision.
ICD-10 and surgical procedure codes, see table 1). Death caused or preceded by CVD within 28 days was defined as CV mortality. Risk of unstable angina pectoris, myocardial infarction, ischaemic heart disease and stroke, as well as all-cause and CV mortality, was studied separately.

\section{Baseline covariates}

Covariates measured at baseline included demographic and socioeconomic status (sex, age, country of birth, marital status, education level, employment status, profession and individual income), morbidities (cancer diagnosis prior to the index date and filled prescriptions for diabetes medications (ATC: A10), anticoagulants (ATC: B01) and/or antihypertensives (ATC: C02, C03, C04, C05, C07, C08, C09)) and clinical characteristics (diabetes duration, glycated haemoglobin (HbAlc), estimated glomerular filtration rate, body mass index (BMI), blood lipid levels, blood pressure, microalbuminuria, macroalbuminuria, physical activity and smoking). Patients with a history of CVD prior to the index date were defined as having used lipid-lowering medications for secondary prevention; all other patients were defined as receiving primary prevention. The selected baseline covariates have previously been shown to be important factors when analysing adherence as well as risk of CVD and mortality. 202324

Socioeconomic characteristics were collected from the LISA database for 12 months before or after the individual's index date. Filled prescriptions for diabetes medications, anticoagulants and antihypertensives were collected from the SPDR for 18 months prior to the index date. Using ICD codes, cancer diagnoses (ICD-10: C00-97) for 5 years prior to the index date were collected from the National Patient Register. Data are often reported to NDR retrospectively, thus blood lipid levels were collected for 24 months before and 14 days after the index date. All other clinical variables were collected from the NDR for 24 months before and 12 months after the index date. To analyse whether the blood lipids changed after commencement of lipid-lowering medications, and whether the potential change differed between MPR levels, follow-up levels were collected at least 30 days after the index date until the final day of the exposure period. Differences in blood lipid levels between baseline and follow-up were analysed for patients with values during both periods (ie, before multiple imputations).

A total of $20.0 \%$ of baseline data were missing; $3.0 \%$ of socioeconomic variables and $36.5 \%$ of clinical characteristics. There were no missing data among variables about morbidities. Multiple imputations by chained equations were used to replace missing data among baseline variables. ${ }^{25}$ Ten imputed data sets were generated by means of 10 iterations per imputation.

\section{Sensitivity analyses}

To estimate the impact of multiple imputations, complete case analysis was performed for original data and descriptively compared with the results of the imputed data. 


\section{Statistical analyses}

The risk of any CVD, unstable angina pectoris, myocardial infarction, stroke, ischaemic heart disease or all-cause and CV mortality was analysed separately by level of MPR, as well as by persistence, using Cox proportional hazards regression adjusted for all baseline covariates. Survival estimates for the 10 imputed data sets were assessed by adjusting for all baseline covariates using Cox proportional hazards regression. Kaplan-Meier survival curves for any CVD and all-cause mortality by MPR level were generated by pooling the survival estimates.

The difference in blood lipids between baseline and follow-up was analysed by level of MPR using a paired t-test. All hypothesis tests were evaluated using a $5 \%$ significance level.

Multiple imputations were performed in R, V.3.3.2, ${ }^{26}$ using the Multivariate Imputation by Chained Equations package. ${ }^{27}$ All other data management and statistical analyses were performed using SAS software V.9.4 (SAS Institute).

\section{RESULTS}

\section{Study population}

A total of 105841 new users of lipid-lowering medications were identified, 86568 of whom were included in the final study population (figure 1). A total of $86.5 \%$ of them received lipid-lowering medications for primary prevention $(n=74909)$. Nearly $80 \%$ of the final study population had been born in Sweden, and more than half were married or living with a partner (table 2). Approximately half of the population had filled prescriptions for diabetes medications. BMI averaged approximately 30 . Among primary prevention patients $(55.4 \%$ men $)$, the mean age was almost 62 years and average diabetes duration was almost 5 years. Secondary prevention patients (65.8\% men) averaged 69 years of age and diabetes duration of nearly 6 years. The mean HbAlc was $53.6 \mathrm{mmol} /$ mol $(7.1 \%)$ among primary prevention patients and $52.7 \mathrm{mmol} / \mathrm{mol}(7.0 \%)$ among secondary prevention patients. A total of $21 \%$ of primary prevention patients and $24 \%$ of secondary prevention patients engaged in physical activity less than once a week. Among primary prevention patients, $25 \%$ filled prescriptions for anticoagulants and 59\% for antihypertensives. Among secondary prevention patients $57 \%$ filled prescriptions for anticoagulants and $67 \%$ for antihypertensives.

\section{Refill adherence and risk of CVD and mortality}

Higher MPR level was associated with increasing age, retirement, prescribing of antihypertensives and non-smoking in primary prevention patients (online supplementary appendix 1). Among secondary prevention patients lower MPR level was associated with increasing unemployment (online supplementary appendix 2). In both patient groups, lower MPR was associated with being born outside of Europe. Otherwise, the baseline characteristics were similar between the MPR levels in both patient groups.
Patients $\geq 18$ years, registered in the NDR, with type 2 diabetes who filled at least one prescription for lipid-lowering medications during 2007-2010 $(n=265,906)$

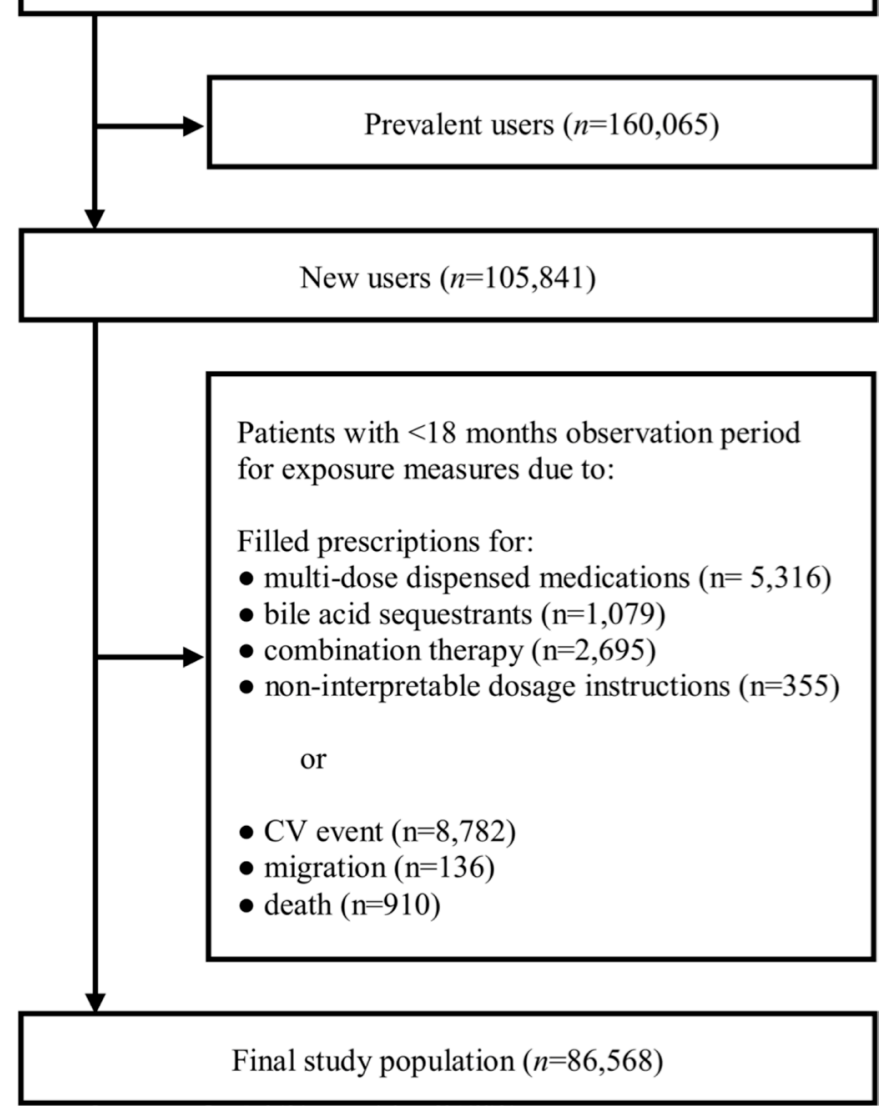

Figure 1 Exclusion criteria for the study population. CV, cardiovascular; NDR, National Diabetes Register.

Six per cent $(n=4350)$ of primary prevention patients and $5 \%(n=545)$ of secondary prevention patients filled only one prescription for lipid-lowering medications. The mean MPR was $77.4 \%$ ( $\mathrm{SD}=26.6$ ) among primary prevention patients and $82.7 \%(\mathrm{SD}=24.7)$ among secondary prevention patients. A total of $78 \%$ of primary prevention patients and $83 \%$ of secondary prevention patients were persistent for 18 months. A total of $6.7 \% \quad(n=5009)$ of primary prevention patients and $32.4 \%(\mathrm{n}=3783)$ of secondary prevention patients experienced a CV event during the outcome period. A total of $5 \%$ of primary prevention patients and $13 \%$ of secondary prevention patients died during the outcome period. Among primary prevention patients, the mean follow-up time was 3.5 years for unstable angina pectoris, myocardial infarction and ischaemic heart disease and 3.6 years for stroke and mortality. Among secondary prevention patients, the mean follow-up time was 3.4 years for unstable angina pectoris, 3.1 years for ischaemic heart disease, 3.5 years for myocardial infarction and stroke and 3.6 years for mortality.

According to the adjusted model, both primary and secondary prevention patients with $\mathrm{MPR} \leq 80 \%$ had a 
Table 2 Baseline characteristics for the study population

\begin{tabular}{|c|c|c|c|c|c|c|}
\hline & \multicolumn{2}{|c|}{$\begin{array}{l}\text { All } \\
n=86568\end{array}$} & \multicolumn{2}{|c|}{$\begin{array}{l}\text { Primary prevention } \\
\mathrm{n}=74909\end{array}$} & \multicolumn{2}{|c|}{$\begin{array}{l}\text { Secondary prevention } \\
n=11659\end{array}$} \\
\hline & $\mathbf{n}$ & $\%$ & $\mathbf{n}$ & $\%$ & $\mathbf{n}$ & $\%$ \\
\hline Male & 49146 & 56.8 & 41470 & 55.4 & 7676 & 65.8 \\
\hline \multicolumn{7}{|l|}{ Age (years) } \\
\hline $61-80$ & 48446 & 56.0 & 40741 & 54.4 & 7705 & 66.1 \\
\hline$>80$ & 4037 & 4.7 & 2591 & 3.5 & 1446 & 12.4 \\
\hline Mean (SD) & 62.9 & $(11.0)$ & 62.0 & (10.9) & 68.5 & (10.2) \\
\hline Median (IQR) & 63.0 & $(15.0)$ & 63.0 & $(15.0)$ & 69.0 & $(14.0)$ \\
\hline \multicolumn{7}{|l|}{ Country of birth } \\
\hline Other EU27 country & 2382 & 2.8 & 2009 & 2.7 & 373 & 3.2 \\
\hline Rest of Europe & 3328 & 3.8 & 2869 & 3.8 & 459 & 3.9 \\
\hline Africa & 1139 & 1.3 & 1048 & 1.4 & 91 & 0.8 \\
\hline The Americas/Oceania & 813 & 0.9 & 733 & 1.0 & 80 & 0.7 \\
\hline Asia & 1231 & 1.4 & 1133 & 1.5 & 98 & 0.8 \\
\hline Middle East country & 3905 & 4.5 & 3521 & 4.7 & 384 & 3.3 \\
\hline \multicolumn{7}{|l|}{ Marital status } \\
\hline Unmarried & 13773 & 15.9 & 12393 & 16.5 & 1380 & 11.8 \\
\hline Postsecondary & 15563 & 18.0 & 13926 & 18.6 & 1637 & 14.0 \\
\hline \multicolumn{7}{|l|}{ Employment status } \\
\hline Unemployed & 12457 & 14.4 & 11037 & 14.7 & 1420 & 12.2 \\
\hline Employed & 43796 & 50.6 & 39730 & 53.0 & 4066 & 34.9 \\
\hline Retired* & 30315 & 35.0 & 24142 & 32.2 & 6173 & 53.0 \\
\hline \multicolumn{7}{|l|}{ Profession } \\
\hline Upper white collar & 25449 & 29.4 & 22272 & 29.7 & 3177 & 27.3 \\
\hline Lower white collar & 7077 & 8.2 & 6264 & 8.4 & 813 & 7.0 \\
\hline Blue collar & 51719 & 59.7 & 44446 & 59.3 & 7273 & 62.4 \\
\hline Others & 2323 & 2.7 & 1927 & 2.6 & 396 & 3.4 \\
\hline \multicolumn{7}{|l|}{ Individual income (TSEK†) } \\
\hline Mean (SD) & 192 & $(285)$ & 195 & $(297)$ & 173 & $(187)$ \\
\hline Median (IQR) & 157 & $(109)$ & 160 & $(112)$ & 139 & (81) \\
\hline \multicolumn{7}{|l|}{ Diabetes medications } \\
\hline No diabetes medications & 38852 & 44.9 & 32951 & 44.0 & 5901 & 50.6 \\
\hline Insulin only & 7137 & 8.2 & 6054 & 8.1 & 1083 & 9.3 \\
\hline
\end{tabular}


Table 2 Continued

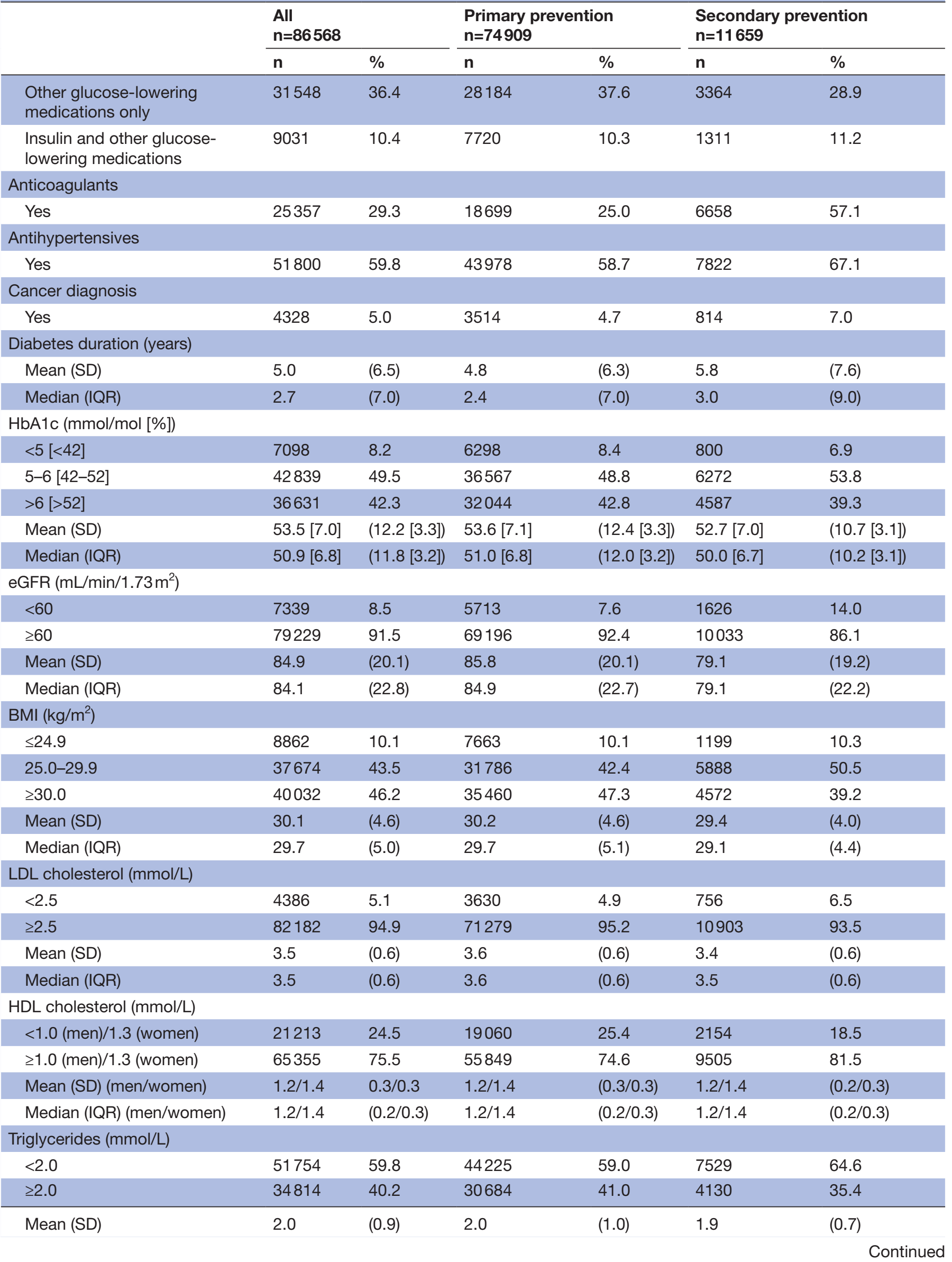


Table 2 Continued

\begin{tabular}{|c|c|c|c|c|c|c|}
\hline & \multicolumn{2}{|c|}{$\begin{array}{l}\text { All } \\
n=86568\end{array}$} & \multicolumn{2}{|c|}{$\begin{array}{l}\text { Primary prevention } \\
n=74909\end{array}$} & \multicolumn{2}{|c|}{$\begin{array}{l}\text { Secondary prevention } \\
n=11659\end{array}$} \\
\hline & $n$ & $\%$ & n & $\%$ & $n$ & $\%$ \\
\hline Median (IQR) & 1.8 & $(0.8)$ & 1.8 & $(0.8)$ & 1.8 & $(0.7)$ \\
\hline \multicolumn{7}{|c|}{ Systolic pressure $(\mathrm{mm} \mathrm{Hg})$} \\
\hline$<130$ & 21068 & 24.3 & 18657 & 24.9 & 2411 & 20.7 \\
\hline$\geq 130$ & 65500 & 75.7 & 56252 & 75.1 & 9248 & 79.3 \\
\hline Mean (SD) & 137.4 & $(14.5)$ & 137.3 & (14.5) & 138.6 & $(14.7)$ \\
\hline Median (IQR) & 136.0 & $(15.0)$ & 135.9 & $(15.0)$ & 138.0 & $(15.0)$ \\
\hline \multicolumn{7}{|c|}{ Diastolic pressure $(\mathrm{mm} \mathrm{Hg})$} \\
\hline$<80$ & 44944 & 51.9 & 37974 & 50.7 & 6970 & 59.8 \\
\hline$\geq 80$ & 41624 & 48.1 & 36935 & 49.3 & 4689 & 40.2 \\
\hline Mean (SD) & 78.7 & $(8.2)$ & 78.9 & $(8.3)$ & 77.4 & $(8.0)$ \\
\hline Median (IQR) & 79.6 & (6.6) & 79.6 & $(6.8)$ & 78.4 & $(5.0)$ \\
\hline \multicolumn{7}{|l|}{ Microalbuminuria } \\
\hline Yes & 8354 & 9.7 & 7097 & 9.5 & 1257 & 10.8 \\
\hline \multicolumn{7}{|l|}{ Macroalbuminuria } \\
\hline Yes & 3096 & 3.6 & 2543 & 3.4 & 553 & 4.7 \\
\hline \multicolumn{7}{|l|}{ Physical activity } \\
\hline$<$ Once per week & 18754 & 21.7 & 15921 & 21.3 & 2833 & 24.3 \\
\hline 1-2 times/week & 16384 & 18.9 & 14223 & 19.0 & 2161 & 18.5 \\
\hline 3-5 times/week & 19435 & 22.5 & 17043 & 22.8 & 2392 & 20.5 \\
\hline Daily & 31995 & 37.0 & 27722 & 37.0 & 4373 & 36.7 \\
\hline \multicolumn{7}{|l|}{ Smoking§ } \\
\hline Yes & 10708 & 12.4 & 9592 & 12.8 & 1116 & 9.6 \\
\hline
\end{tabular}

*If aged $\geq 65$ years and unemployed.

†One TSEK is equal to approximately US $\$ 119$.

$\ddagger 30$ min walk or equivalent.

$\S A t$ least one cigarette or pipe per day or stopped smoking within 3 months.

BMI, body mass index; eGFR, estimated glomerular filtration rate; HbA1c, glycated haemoglobin (A1c); HDL, high-density lipoprotein; LDL,

low-density lipoprotein; TSEK, thousands of Swedish krona.

greater risk of unstable angina pectoris, myocardial infarction, ischaemic heart disease and stroke than patients with MPR $>80 \%$, and the risk gradually increased with lower adherence (table 3). Compared with patients with MPR $>80 \%$, the risk of any CVD was double among primary prevention patients with MPR $\leq 40 \%$ and between $33 \%$ and $52 \%$ in primary prevention patients with MPR of $41 \%-80 \% \quad(p<0.0001)$. The same comparison for secondary prevention patients showed a 19\%-58\% increased risk of any CVD between the MPR levels $(\mathrm{p}<0.0001)$. Compared with patients with MPR $>80 \%$, the risk of CV mortality was $18 \%-26 \%$ among primary prevention patients (except for MPR 41\%-60\%, which showed no statistically significant difference) and $19 \%-48 \%$ in secondary prevention patients $(\mathrm{p}<0.0001)$.

Furthermore, 18-month persistence was associated with a lower risk of CVD and mortality among both primary and secondary prevention patients (table 4 ). Among non-persistent patients, the risk of any CVD and CV mortality was $64 \%$ and $15 \%$ higher, respectively, for primary prevention patients, and $33 \%$ and $29 \%$ higher, respectively, for secondary prevention patients $(\mathrm{p}<0.0001)$ compared with persistent patients.

Considering all baseline covariates, the Kaplan-Meier survival curves showed higher survival of any CVD and higher MPR levels in both primary and secondary prevention patients (figure 2). For all-cause mortality, the survival curves showed similar rates between the MPR levels.

\section{Change in blood lipid levels}

Approximately $30 \%$ of primary prevention patients and $20 \%$ of secondary prevention patients had registered blood lipid values at baseline and follow-up. Mean low-density lipoprotein (LDL) cholesterol at baseline was $3.5-3.6 \mathrm{mmol} / \mathrm{L}$ for primary prevention patients and $3.2-3.4 \mathrm{mmol} / \mathrm{L}$ for secondary prevention patients. All in all, LDL cholesterol was significantly lower at follow-up than baseline, with exception of secondary prevention patients with MPR of 21\%-40\%, for whom no change was observed $(\mathrm{p}<0.05)$. Average LDL cholesterol gradually 


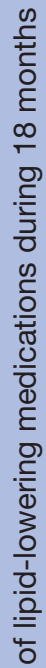

:

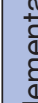

일

을

ญ

$\frac{\bar{d}}{\frac{1}{\bar{D}}}$

实

प्र

ब

a

곤

들

들

$\stackrel{\infty}{\stackrel{5}{\frac{1}{5}}}$

गे

$\frac{\mathscr{n}}{\underline{I}}$

$\frac{\sqrt{n}}{\frac{\pi}{0}}$

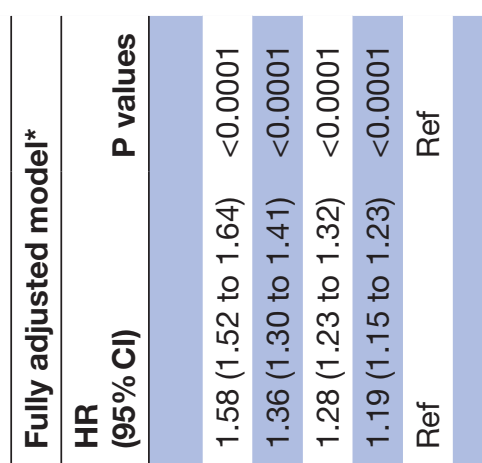

훙

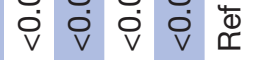

क्ष

广́

吕

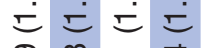

宓

旁 $\overline{8} \overline{8} \overline{8}$

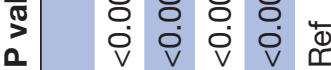

ฬ ণ

ㄷ. 단

उ) 웅ㅇ

ठำ ㅇำ

을 Е Е

गे

गั

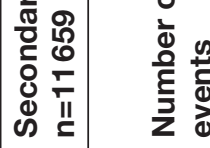

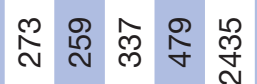

훙 훙 훙

$\frac{k}{d}$
$\frac{\pi}{8}$
$\frac{8}{\xi}$

a $\quad$ V

สิ ชิ ชิ

ఫ

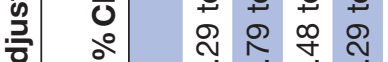

\บ $=$

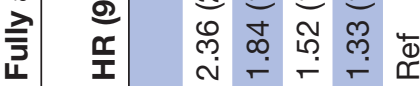

흥 흥 훙

v $\begin{gathered}0 \\ \dot{0}\end{gathered}$

$a$

จิ ลิ

ก

$\widehat{\overline{0}}$

오 오 오 오

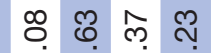

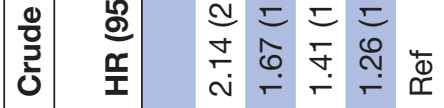

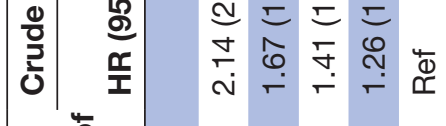

등

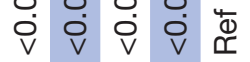

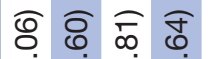

우 우 오 우

○

ᄃ $ᄃ 5$

ำ 웅 운

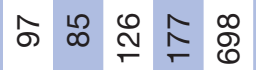

형 흥 훙

vं

ঔ จ

ㄱ $\sim$

우우 우 우

당 우 아

i $=\check{5}$

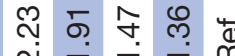

흥 형 흥

vं

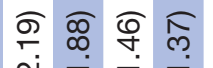

오 오 오 우

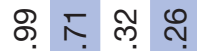

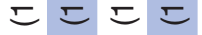

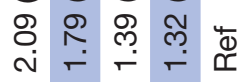

ก

r

ง

등 훙효

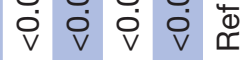

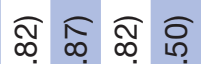

ง

$+ㅇ ㅇ ㅇ$

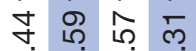

들

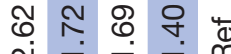

훙 훙

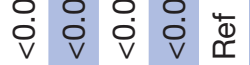

สิ

ก $\leftarrow$ -

웅ㅇ 우우

オ

i $ᄃ=$

đֶ

훙ㅎㅇㅇㅎㅇ

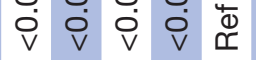

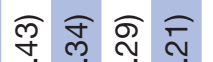

гं

ㄴำ

ᄃ $匚$ Е

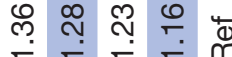

훙ㅎㅇ 훙

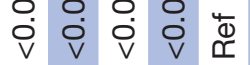

চ̄

v 0 i 0

হু হু চ্চি

ง

오오 우 우

๙ิ Г 이 ஜ

ᄃ $匚$ ᄃ

人ิ

बิ ส

다

오 우 우 우

mํำ

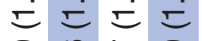

ঙำ

$\bar{\delta} \bar{\delta} \bar{\delta}$

守

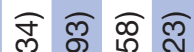

त $\leftarrow \div$

아오 우우

ஜิ $\hat{0} \hat{\circ}$

$\mathbb{N}=E$

$\infty \circ$ 子

त̀

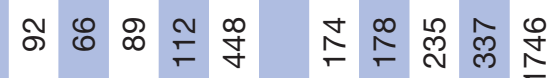

๓

흥 훙 훙

vं $\left.\begin{array}{l}0 \\ \dot{0}\end{array}\right)$

흥ㅎㅇ

Vं

চ் $\bar{\varnothing} \bar{\varnothing}$

v $\dot{v} \dot{v} \dot{v}$

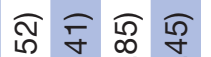

ल

웅ㅇㅇㅇㅇ

กิ

ल 드 ᄃ

ले शे श्र ले

สิ่

아 $\widehat{ }$

ง

우우 우

으요 주

드 ᄃ

于

ง

아용ㅇㅇㅜ

$\infty \Leftrightarrow$ 우

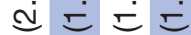

จำ 守

लं

흥 흥 훙

vं

흥 훙 훙

vं $\begin{aligned} & 0 \\ & \text { V }\end{aligned}$

흥

จ

ลิ

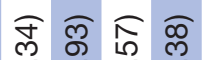

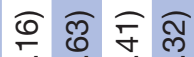

ल $\mathrm{N} \leftarrow$

아 오 우 우

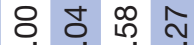

m $\simeq ᄃ$

N T T T

i $T \Gamma$

우 우오 웅

아우 우우

m

品 ิ Nิ

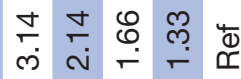

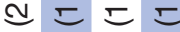

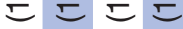

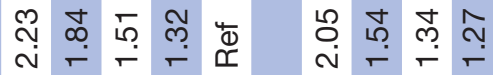

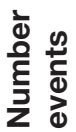

స

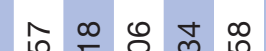

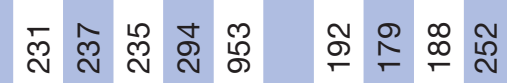
弥

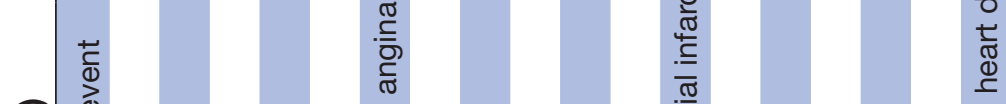

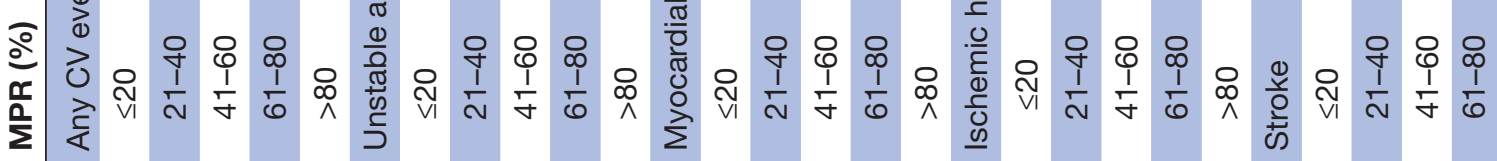




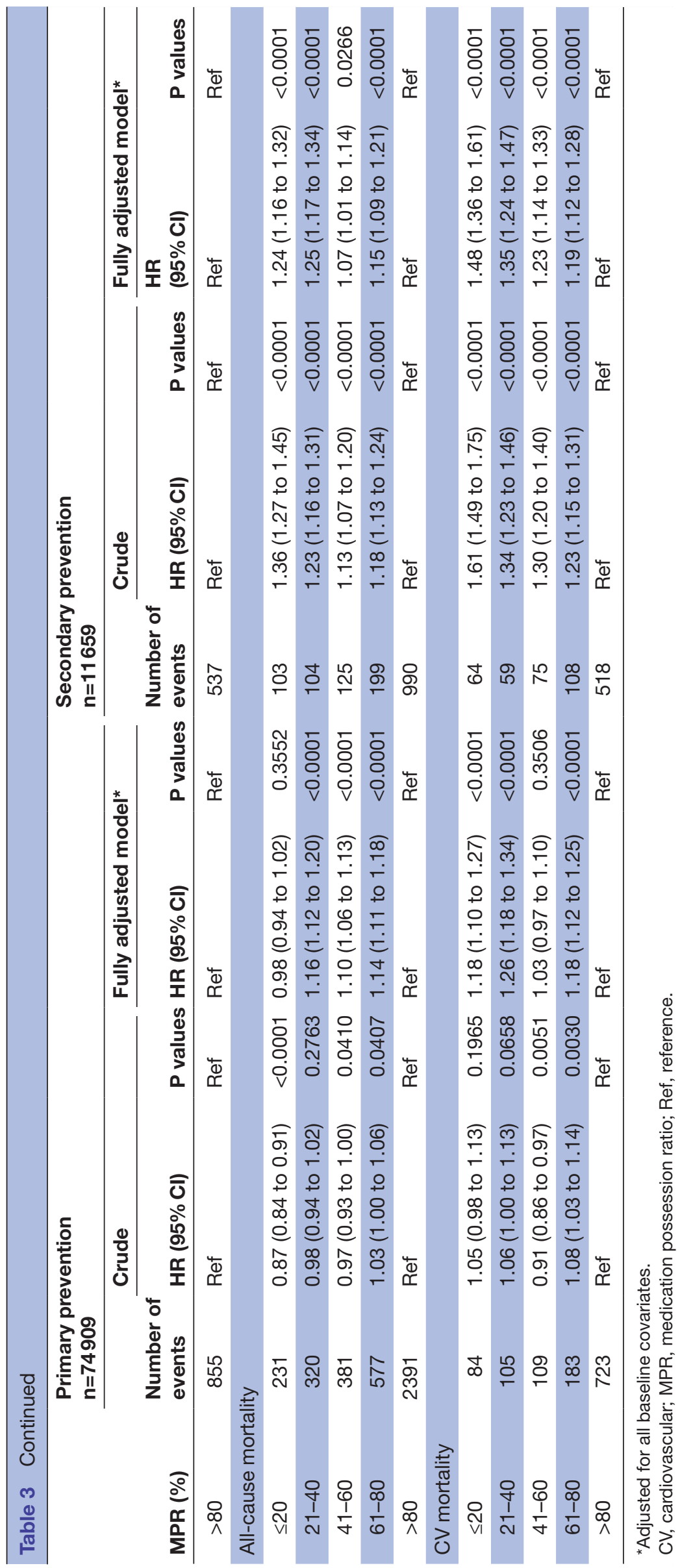




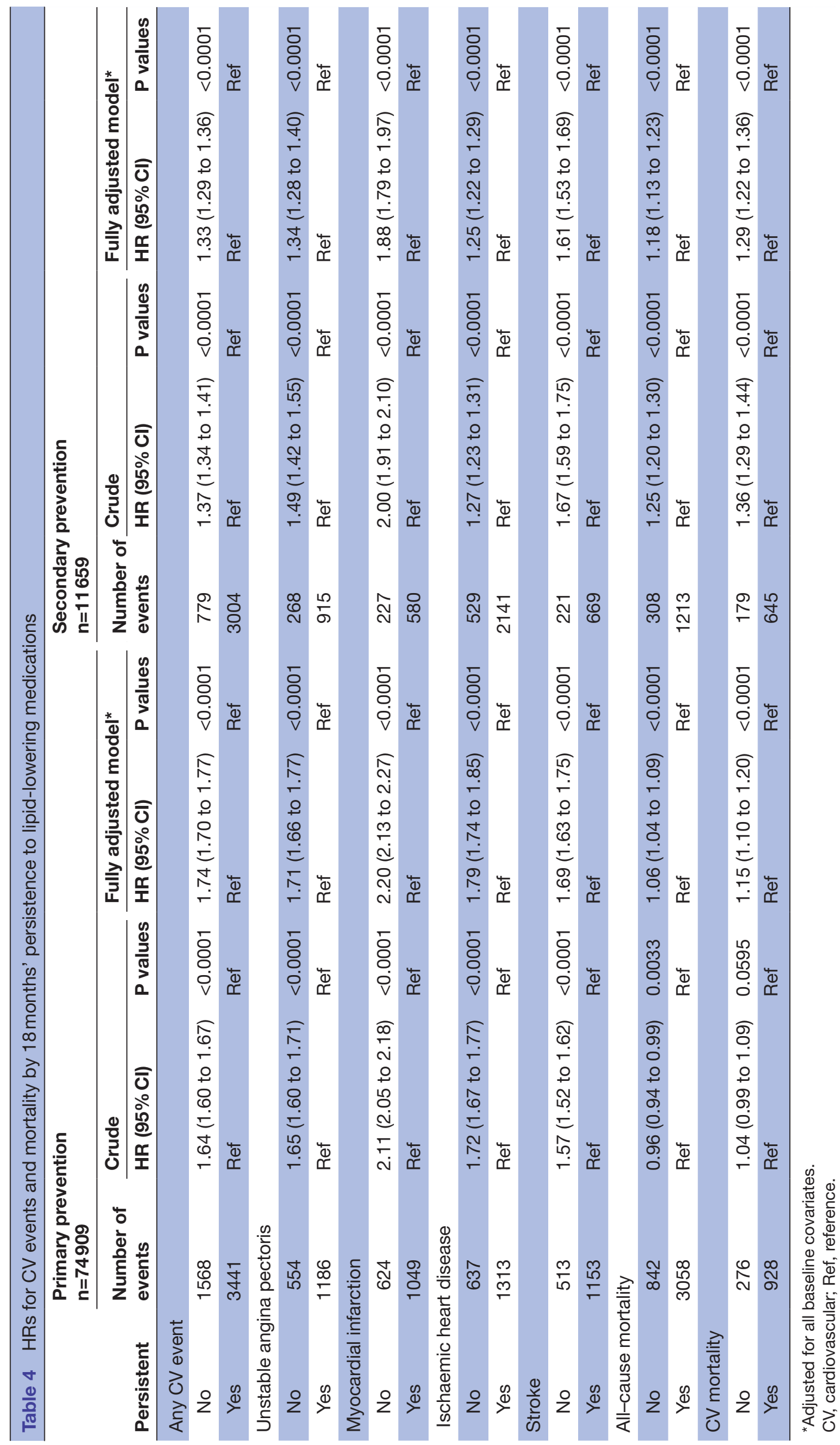



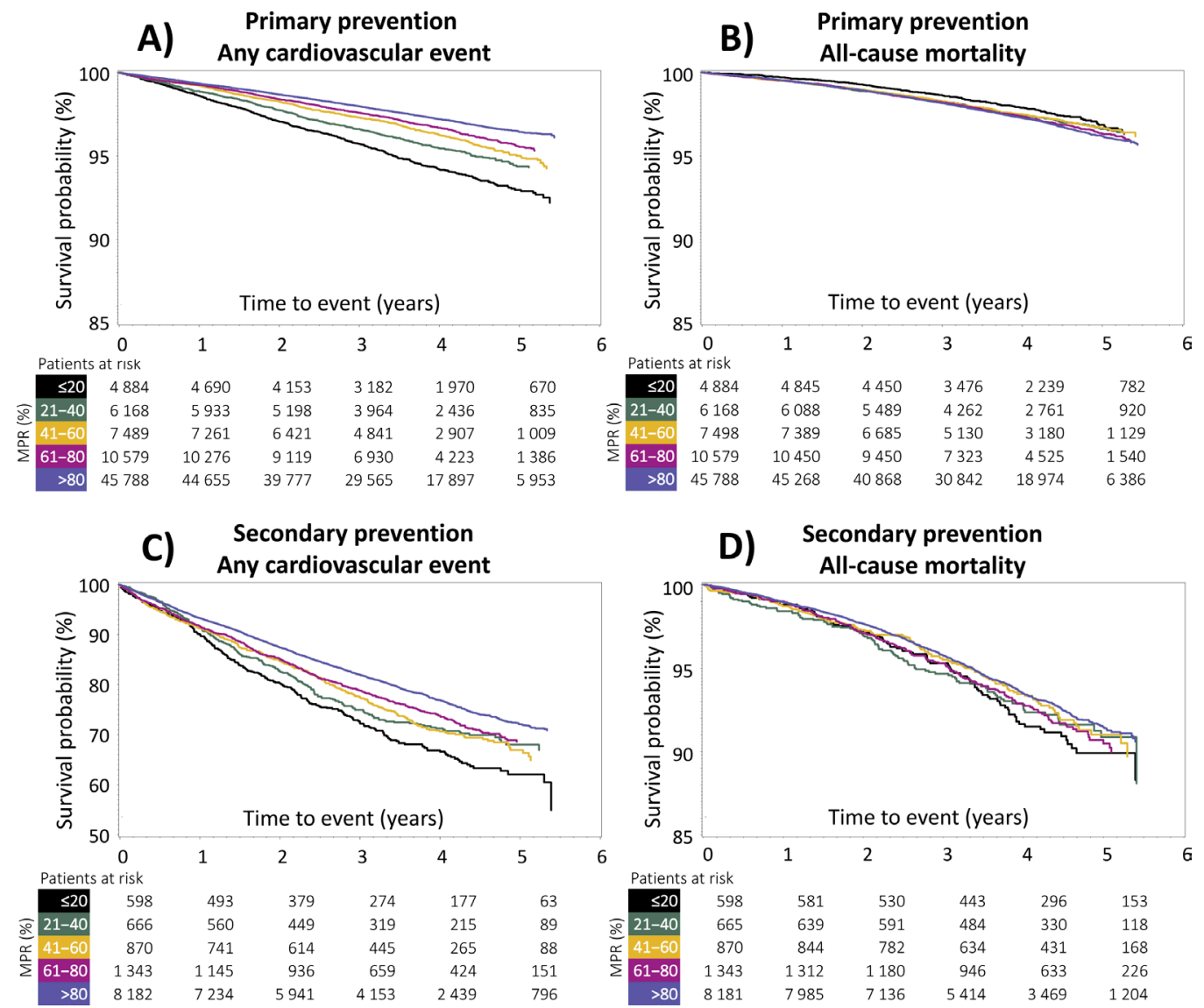

Figure 2 Survival probability by medication possession ratio (MPR) level adjusted for potential confounders. Survival probability ranging from $85 \%$ to $100 \%$ for any cardiovascular event (A) and all-cause mortality (B) in primary prevention patients as well as for all-cause mortality (D) in secondary prevention patients. Survival probability ranging from $50 \%$ to $100 \%$ for any cardiovascular event (C) in secondary prevention patients.

decreased with higher levels of MPR among both primary and secondary prevention patients. Little or no statistically significant change was found in high-density lipoprotein cholesterol and triglycerides. Changes in blood lipid levels between baseline and follow-up by level of refill adherence during implementation of lipid-lowering medications are presented in table 5 .

\section{Sensitivity analyses}

Adjusted for all baseline covariates in original data, 22.8\% of primary prevention patients $(n=17058)$ and $13.6 \%$ of secondary prevention patients $(n=1591)$ were included in complete case analyses. The risk of CVD was similar between original and imputed data; patients with MPR $\leq 80 \%$ faced a higher risk than those with MPR $>80 \%$, and the risk increased with lower adherence. Moreover, 18-month persistence to lipid-lowering medications was associated with a lower risk of CVD in both prevention groups. However, the CIs were wider in complete case analyses. There was no statistically significant difference in the risk of mortality by MPR level or persistence in complete case analyses. HRs for complete cases are presented by level of refill adherence during implementation in online supplementary appendix 3 and by persistence in online supplementary appendix 4 .

\section{DISCUSSION}

This nationwide study involving 86568 patients with type 2 diabetes mellitus showed a higher risk of unstable angina pectoris, myocardial infarction, stroke and ischaemic heart disease, as well as all-cause and CV mortality, with lower levels of refill adherence during implementation of lipid-lowering medications in both primary and secondary prevention patients. Furthermore, non-persistence to treatment was associated with a higher risk of CVD and mortality as well. To our knowledge, this is the largest cohort study of the association between risk of CVD and mortality by level of refill adherence during implementation and persistence to lipid-lowering medications among patients with type 2 diabetes mellitus.

The present study found that patients with MPR of $80 \%$ or less had an increased risk of CVD and CV mortality. These results are consistent with previous studies showing that patients with diabetes mellitus with adherence during implementation below $80 \%$ had an increased risk of major coronary events, ${ }^{5}$ ischaemic stroke ${ }^{6}$ and mortality, ${ }^{15}$ compared with patients with an implementation of at least $80 \%$. However, the studies provide no information about whether the risk differs between patients with a level of adherence during implementation 


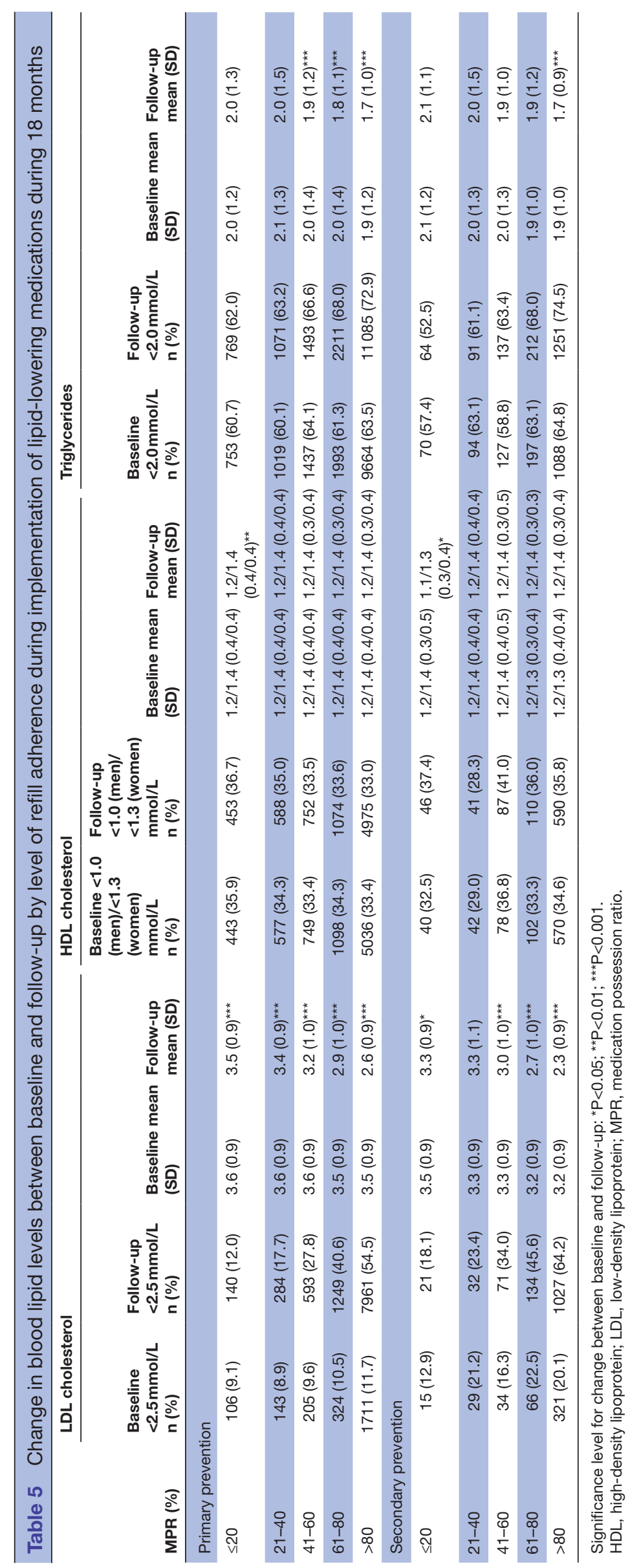


below $80 \%$. The present study demonstrates that the risk of all CVD outcomes gradually increases with lower levels of refill adherence during implementation. This finding emphasises the benefits of maximising adherence. The results suggest that reduced adherence still seems beneficial compared with non-adherence. Nevertheless, the benefit is significantly less than among patients with high adherence to lipid-lowering medications.

There is always a reason for poor adherence and healthcare professionals should take it into consideration as possible cause of failed therapy. First and foremost, attention needs to be directed towards patients who fail to initiate therapy. Second, premature discontinuation needs to be prevented. In the present study, about 5\% of the study population filled only one prescription for lipid-lowering medications, and overall between $16 \%$ and $22 \%$ was considered non-persistent. Statins (the most frequently prescribed class of lipid-lowering medications) have been hypothesised to pose an unwarranted risk of adverse effects, particularly muscle pain or weakness. ${ }^{28}$ However, several studies have shown that these claims are exaggerated and that the risk of adverse effects of statins is often due to dose or when used in combination with other medications. A recent study showed no significant difference between the reported rate of adverse effects due to statin therapy and placebo when use was double blinded. ${ }^{29}$ Only when patients and their doctors were aware that statins were being used was a higher rate of muscle-related adverse effects observed. Negative media coverage can be linked to a reduction in statin prescription, as well as discontinuation by patients. ${ }^{28}$ The result is insufficient treatment of patients at risk of developing CVD, which increases the risk of serious morbidity and boosts public health costs. Doctors and patients should certainly be aware that statins can have adverse effects. However, dose adjustments or changing medications can eliminate many of them, as opposed to myocardial infarction or stroke, the consequences of which may be irreversible. Informing patients with type 2 diabetes about the benefits and disadvantages of statins, and discussing available treatment options have been shown to improve patients' risk perception of CVD and increase their involvement in clinical decisions. ${ }^{30} 31$

The CVD risk reduction in patients with type 2 diabetes mellitus is not only associated with adherence to lipid-lowering medications; high adherence to glucose-lowering medications $^{32}$ and/or antihypertensives ${ }^{33}$ is also associated with lower risk of CVD. However, our results indicate that lipid-lowering medications play a major role in the treatment of patients with type 2 diabetes mellitus. The question of whether moderate risk reduction of several risk factors is more effective in reducing the overall CVD risk than a major reduction of one risk factor remains to be further studied.

\section{Strengths}

The greatest strengths of this study are the large population, national scope and ability to analyse the association between risk of CVD and mortality at five different levels of refill adherence during implementation. Furthermore, we assessed refill adherence over a period of 18 months, a rather long time from an international perspective. Previous studies of refill adherence had recommended that the length of a study period correspond to at least six filled prescriptions. ${ }^{34}$ The Swedish Pharmaceutical Benefit Scheme permits no more than a 3-month supply to be dispensed at a time following consumption of two-thirds of the previous fill. ${ }^{22}$ That is the most common amount for lipid-lowering medications. The exposure period was set to 18 months, as recommended by previous studies of statins for the general Swedish population. ${ }^{35}$

\section{Limitations}

In order to ensure a chronological sequence between exposure and outcomes, we estimated adherence in a different period than when CVD and mortality might occur. After the exposure period, each patient was followed and assessed for outcomes during a period of at least 18 months. A potential drawback of this strategy is that only patients who survived the exposure period were eligible for inclusion in the analysis. In other words, we may have introduced a selection bias that excluded highly fragile patients.

The study population was limited to patients with type 2 diabetes mellitus who filled prescriptions for lipid-lowering medications as monotherapy. Thus, we were not able to assess the extent of primary non-adherence, that is, patients who did not fill the initial prescription. Furthermore, patients on lipid-lowering combination therapy (2.7\% of all new users) were not included. Only patients with several risk factors for CVD who do not reach the target values for LDL cholesterol with monotherapy are recommended for combination therapy. We also excluded patients with multidose dispensed medications, typically for those aged 65 years and older. As a result, our study population might be younger and have less comorbidity than the general cohort of Swedish patients with type 2 diabetes mellitus who commence lipid-lowering medication use.

Another limitation of the study stems from missing data on the baseline covariates adjusted for in the statistical analyses. However, sensitivity analyses between imputed data and the complete case analyses from original data showed similar results. Thus, the impact on our final conclusions appears to be limited.

\section{CONCLUSIONS}

This study shows that higher levels of refill adherence are associated with lower risk of CVD in patients with type 2 diabetes mellitus, who commence lipid-lowering medications for primary or secondary prevention. New knowledge has thus been acquired concerning the gradual difference in risk reduction by level of adherence, thereby reinforcing previous evidence of the advantages of high adherence to lipid-lowering medications for prevention 
of CVD. Healthcare professional can use the information to better motivate patients with diabetes mellitus to follow their recommended treatment.

Acknowledgements The authors thank Ken Schubert, Twenty-First Century Translation and Editing, for the linguistic editing.

Contributors SAK, CH, AMS, SF, MM, SG, KEO, BE and KAS contributed to the study design and the implementation of the research, to the analysis and the implementation of the results, and the writing of the manuscript. AMS and MM linked and compiled the data. SAK and SF performed the statistical analyses. SAK and KAS drafted the manuscript. KAS is the guarantor of the study.

Funding This study was funded by a grant from the Swedish Research Council for Health, Working Life and Welfare (number: 2013-0521).

Disclaimer The views expressed in this submitted manuscript are those of KAS and not those of AstraZeneca's.

Competing interests KAS is employed by AstraZeneca. KEO reports personal fees from Abbott, outside the submitted work.

Patient consent Detail has been removed from this case description/these case descriptions to ensure anonymity. The editors and reviewers have seen the detailed information available and are satisfied that the information backs up the case the authors are making.

Ethics approval The Regional Ethical Review Board at the University of Gothenburg.

Provenance and peer review Not commissioned; externally peer reviewed.

Data sharing statement № additional unpublished data are available.

Open Access This is an Open Access article distributed in accordance with the Creative Commons Attribution Non Commercial (CC BY-NC 4.0) license, which permits others to distribute, remix, adapt, build upon this work non-commercially, and license their derivative works on different terms, provided the original work is properly cited and the use is non-commercial. See: http://creativecommons.org/ licenses/by-nc/4.0/

(C) Article author(s) (or their employer(s) unless otherwise stated in the text of the article) 2018. All rights reserved. No commercial use is permitted unless otherwise expressly granted.

\section{REFERENCES}

1. Rawshani A, Rawshani A, Franzén S, et al. Mortality and cardiovascular disease in Type 1 and Type 2 diabetes. N Engl J Med Overseas Ed 2017;376:1407-18.

2. World Health Organization. Global report on diabetes. Geneva, 2016. http://www.who.int/diabetes/global-report/en/

3. American Diabetes Association. 9. Cardiovascular disease and risk management. Diabetes Care 2017;40(Suppl 1):S75-S87.

4. International Diabetes Federation. Cardiovascular risk protection. Global guideline for Type 2 Diabetes. Brussels, 2012. http://www.idf. org

5. Ruokoniemi P, Korhonen MJ, Helin-Salmivaara A, et al. Statin adherence and the risk of major coronary events in patients with diabetes: a nested case-control study. Br J Clin Pharmacol 2011;71:766-76.

6. Korhonen MJ, Ruokoniemi P, Ilomäki J, et al. Adherence to statin therapy and the incidence of ischemic stroke in patients with diabetes. Pharmacoepidemiol Drug Saf 2016;25:161-9.

7. De Vera MA, Bhole V, Burns LC, et al. Impact of statin adherence on cardiovascular disease and mortality outcomes: a systematic review. Br J Clin Pharmacol 2014;78:684-98.

8. Vrijens B, De Geest S, Hughes DA, et al. A new taxonomy for describing and defining adherence to medications. Br J Clin Pharmacol 2012;73:691-705.

9. World Health Organization. Adherence of long-term therapies: evidence for action. Geneva 2003 http://www.who.int/chp/ knowledge/publications/adherence_report/en/.

10. Osterberg L, Blaschke T. Adherence to medication. N Engl J Med 2005;353:487-97.

11. Cramer JA, Roy A, Burrell A, et al. Medication compliance and persistence: terminology and definitions. Value Health 2008;11:44-7.
12. Helin-Salmivaara A, Lavikainen P, Ruokoniemi $P$, et al. Persistence with statin therapy in diabetic and non-diabetic persons: a nationwide register study in 1995-2005 in Finland. Diabetes Res Clin Pract 2009;84:e9-e11.

13. Ruokoniemi P, Sund R, Arffman M, et al. Are statin trials in diabetes representative of real-world diabetes care: a population-based study on statin initiators in Finland. BMJ Open 2014;4:e005402.

14. Chowdhury R, Khan H, Heydon E, et al. Adherence to cardiovascular therapy: a meta-analysis of prevalence and clinical consequences. Eur Heart J 2013;34:2940-8.

15. Ho PM, Magid DJ, Masoudi FA, et al. Adherence to cardioprotective medications and mortality among patients with diabetes and ischemic heart disease. BMC Cardiovasc Disord 2006;6:48.

16. Wettermark B, Hammar N, Fored CM, et al. The new Swedish prescribed drug register-opportunities for pharmacoepidemiological research and experience from the first six months. Pharmacoepidemiol Drug Saf 2007;16:726-35.

17. Eliasson B, Gudbjörnsdottir S. Diabetes care-improvement through measurement. Diabetes Res Clin Pract 2014;106 (Suppl 2):S291-S294.

18. National Board of Health and Welfare. The National Patient Register. http://www.socialstyrelsen.se/register/halsodataregister/ patientregistret/inenglish (accessed 1 Apr 2015).

19. Statistics Sweden. Longitudinal integration database for health insurance and labour market studies (LISA by Swedish acronym). http://www.scb.se/lisa-en (accessed 1 Apr 2015).

20. Ekström N, Svensson AM, Miftaraj M, et al. Cardiovascular safety of glucose-lowering agents as add-on medication to metformin treatment in type 2 diabetes: report from the Swedish National Diabetes Register. Diabetes Obes Metab 2016;18:990-8.

21. Eliasson B, Ekström N, Bruce Wirta S, et al. Metabolic effects of Basal or premixed insulin treatment in 5077 insulin-naïve type 2 diabetes patients: registry-based observational study in clinical practice. Diabetes Ther 2014;5:243-54.

22. The Dental and Pharmaceutical Benefits Agency. Ordinance (2002:687) on Pharmaceutical Benefits, etc. SFS 2002;2002.

23. Karlsson SA, Hero C, Eliasson B, et al. Refill adherence and persistence to lipid-lowering medicines in patients with type 2 diabetes: A nation-wide register-based study. Pharmacoepidemiol Drug Saf 2017;26:1220-32.

24. Ekström N, Schiöler L, Svensson AM, et al. Effectiveness and safety of metformin in 51675 patients with type 2 diabetes and different levels of renal function: a cohort study from the Swedish National Diabetes Register. BMJ Open 2012;2:e001076.

25. Azur MJ, Stuart EA, Frangakis $C$, et al. Multiple imputation by chained equations: what is it and how does it work? Int $J$ Methods Psychiatr Res 2011;20:40-9.

26. Core Team R. R: a language and environment for statistical computing. Vienna, 2013. http://www.r-project.org/

27. Buuren Svan, Groothuis-Oudshoorn K. Mice : Multivariate imputation by chained equations in R. J Stat Softw 2011;45:1-67.

28. Collins R, Reith C, Emberson J, et al. Interpretation of the evidence for the efficacy and safety of statin therapy. Lancet 2016;388:2532-61.

29. Gupta A, Thompson D, Whitehouse A, et al. Adverse events associated with unblinded, but not with blinded, statin therapy in the Anglo-Scandinavian Cardiac Outcomes Trial-Lipid-Lowering Arm (ASCOT-LLA): a randomised double-blind placebo-controlled trial and its non-randomised non-blind extension phase. Lancet 2017;389:2473-81.

30. Perestelo-Pérez L, Rivero-Santana A, Boronat M, et al. Effect of the statin choice encounter decision aid in Spanish patients with type 2 diabetes: A randomized trial. Patient Educ Couns 2016;99:295-9.

31. Buhse S, Mühlhauser I, Heller T, et al. Informed shared decisionmaking programme on the prevention of myocardial infarction in type 2 diabetes: a randomised controlled trial. BMJ Open 2015;5:e009116.

32. Khunti K, Seidu S, Kunutsor S, et al. Association between adherence to pharmacotherapy and outcomes in type 2 diabetes: a metaanalysis. Diabetes Care 2017;40:1588-96.

33. Cramer JA, Benedict A, Muszbek N, et al. The significance of compliance and persistence in the treatment of diabetes, hypertension and dyslipidaemia: a review. Int J Clin Pract 2008;62:76-87.

34. Andrade SE, Kahler KH, Frech F, et al. Methods for evaluation of medication adherence and persistence using automated databases. Pharmacoepidemiol Drug Saf 2006;15:565-74.

35. Lesén E, Sandström TZ, Carlsten A, et al. A comparison of two methods for estimating refill adherence to statins in Sweden: the RARE project. Pharmacoepidemiol Drug Saf 2011;20:1073-9. 